\title{
Vascular endothelial growth factor as a marker of endothelial dysfunction in poly- and comorbidity: focus on hypertension, type 2 diabetes mellitus and subclinical hypothyroidism
}

\author{
Valeriya Nemtsova', Olexandr Bilovol', Anna Shalimova,", \\ ${ }^{1}$ Kharkiv National Medical University, Kharkiv, Ukraine \\ ${ }^{2}$ The Government Institution 'L.T. Malaya Therapy National Institute of the National Academy of Medical Sciences of Ukraine', Kharkiv, Ukraine
}

\section{Abstract}

Background. The goal of our study was to investigate the content and particularities of change of vascular endothelial growth factor-A (VEGF-A) levels as a marker of endothelial dysfunction (ED) in patients with hypertension (HT) with or without type 2 diabetes mellitus (T2DM) and with or without subclinical hypothyroidism (SH).

Material and methods. Two hundred and eleven patients with hypertension stage II were divided into 3 groups: Group 1 - with HT ( $=55)$; Group 2 - with AH and T2DM ( $=97)$; Group 3 - with HT, T2DM and SH $(\mathrm{n}=59)$. The patients in Group 3 were divided into 3 subgroups depending on TSH levels: $3 \mathrm{a}(\mathrm{n}=26)-$ TSH 4.0-6.0 mIU/L; 3b ( $\mathrm{n}=20)-$ TSH 6.1-8.0 mIU/L; 3c $(\mathrm{n}=13)-\mathrm{TSH} 8.1-10.0 \mathrm{mIU} / \mathrm{L}$. We evaluated lipids, carbohydrate metabolism, serum insulin concentration, insulin resistance index - HOMA, and the level of VEGF-A in plasma.

Results. The levels of VEGF-A in Group 2 was significantly lower vs. Group1 $(323.94 \pm 22.17 \mathrm{pg} / \mathrm{mL}$ and $413.15 \pm 29.02 \mathrm{pg} / \mathrm{mL}$, respectively $(\mathrm{p}<0.05))$. The patients in Group 3d had lower VEGF-A levels than the patients in Group 1, but higher than those in Group 2. Among Group 3 patients, the levels of VEGF-A were the lowest in the 3 a subgroup $(375.91 \pm 19.81 \mathrm{pg} / \mathrm{mL})$, significantly different from $3 \mathrm{~b}$ and $3 \mathrm{c}$ subgroups $(p<0.05)$, for which no differences were found ( $p>0.05$.). In the 3a subgroup VEGF-A levels were significantly higher than in Group 2 patients $(\mathrm{p}<0.05)$.

Conclusion. These data confirms the hypothesis of increasing ED in hypothyroidism even at the subclinical level.

Key words: arterial hypertension; type 2 diabetes mellitus; subclinical hypothyroidism; endothelial dysfunction; vascular endothelial growth factor 


\section{Introduction}

In recent years studies have convincingly proved an important and independent role of the endothelium in the development of cardiovascular (CV) diseases. It plays an extremely important role in the development of atherosclerotic changes in the vascular wall, vessel remodeling and angiogenesis $[1,2]$. Endothelial dysfunction (ED) has proved to be associated with a large number of different factors and pathological conditions such as age, postmenopause, hypercholesterolemia and hypertriglyceridemia, diabetes mellitus, smoking, and arterial hypertension (HT). It is important that the risk of ED development increases both because of an increase in the total number of risk factors (RF) and their combination.

There are a large number of ED plasma markers. One of the recognized ED biomarkers is vascular endothelial growth factor A (VEGF-A). There is evidence that VEGF-A plays an important role in CV diseases, in particular in hypertension it promotes vascular wall remodeling $[2,3]$. It is believed, that detection of this indicator in serum is the earliest marker for ED development, when even active intravascular inflammation has not yet begun. VEGF-A is an important bioactive substance involved in the development of vascular complications in diabetes mellitus (DM). However, currently available data on VEGF-A levels in DM and its complications are quite controversial. Some studies describe both the increase and the decrease in VEGF-A levels in DM. VEGF-A has been successfully used to treat ischemia with diabetic limb lesions. On the other hand, inhibition of VEGF-A was used in diabetic retinopathy [4].

For several decades HT has taken the leading place among CV diseases. It is worth noting that today isolated HT is relatively infrequent. Usually, clinicians have to deal with clinical situations when HT is associated with other diseases, in particular with endocrinopathies, primarily with DM and thyroid diseases, whose number in Ukraine is constantly increasing.

It is believed that, along with type 2 diabetes mellitus (T2DM), hypothyroidism, including subclinical $(\mathrm{SH})$, makes a significant contribution to the formation of cardiometabolic RFs, which determine the prognosis for $\mathrm{AH}$, coronary heart disease $(\mathrm{CHD})$, and other conditions. It is believed that HT and carbohydrate metabolism disorders are pathogenetically interrelated. It is likely that their pathological effects are also realized through ED.

There is no doubt that the mechanisms of ED development in comorbid pathology are complicated and insufficiently studied [1]. Of particular interest is the study of comorbid conditions, each of which is characterized by the presence of ED in the pathogenesis and factors that exacerbate it, which may manifest itself in the enhancement of VEGF-A expression and obviously play an important role in understanding the commonality of pathogenetic processes and developing more effective preventive and therapeutic measures.

The purpose of our study was to determine the levels and features of VEGF-A as a marker of endothelial dysfunction in patients with hypertension in combination with T2DM and $\mathrm{SH}$.

We will test the hypothesis that hypothyroidism (even subclinical) will increase in ED.

\section{Material and methods}

The study included 211 patients $(83$ males and 128 females) aged 40 to 75 (mean age $59.4 \pm 3.7$ years) with HT stage II. All patients were divided into 3 groups according to comorbidity: Group 1 - 55 patients with isolated HT (comparison group); Group $2-97$ patients with $\mathrm{AH}$ in combination with T2DM; Group $3-59$ patients with HT in combination with T2DM and SH. An obligatory criterion for patients of the Group 3 was SH developed as a result of autoimmune thyroiditis (AIT); T2DM was well controlled in all diabetic patients. The control group consisted of 20 healthy individuals, matched for age and sex.

Exclusion criteria were symptomatic hypertension, uncontrolled hypertension, type 1 diabetes and other endocrine disorders, clinical signs of coronary heart diseases or severe concomitant chronic diseases. Also, exclusion criteria were taking iodine medications, glucocorticoids, amiodarone, lithium medications, medication containing estrogens, pregnancy, patients with a previously diagnosed manifested hypothyroidism or $\mathrm{SH}$, patients receiving hormone replacement therapy after surgical treatment of thyroid gland.

In all patients hypertension was confirmed using the European Society of Hypertension (ESH) and the European Society of Cardiology (ESC) guidelines (2018) [5].The diagnosis of SH and T2DM was established in accordance with the approved Order of the Ministry of Health of Ukraine No. 356 dated May 22, 2009 On approval of protocols for the provision of medical care to patients with endocrine diseases [6], Order of the Ministry of Health of Ukraine No. 1118 dated December 21, 2012 On Approval and implementation of medical-technological 
documents for the standardization of medical aid in type 2 diabetes [7] and in accordance with the European Thyroid Association (ETA, 2013) and the American Diabetes Association and the European Association for the Study of Diabetes (2015) guidelines $[8,9]$.

All patients received basic therapy in accordance with international and national guidelines for the management of patients with the corresponding pathology [5-9], on a background of dietary recommendations. All patients had received antihypertensive therapy for at least 6 months before they were included in the study and received an individuallyselected dose of an angiotensin-converting enzyme inhibitor or angiotensin II receptor blocker (ACE inhibitors/ARB) and a diuretic (indapamide); some of the patients additionally received a calcium antagonist (amlodipine or lercanidipine). As an antidiabetic therapy, patients with T2DM received metformin in individually-selected doses from 1000.0 to $2000.0 \mathrm{mg} /$ day; 5 patients (3.21\%) additionally used an agonist of glucagon-like peptide-1 (GLP-1) and 3 patients (1.92\%) - an inhibitor of type 2 sodiumglucose transporter (SGLT2).

All patients underwent anthropometric measurements [height, body weight, body mass index (BMI) according to the Kettle index: $B M I=$ weight $(\mathrm{kg}) /$ lheight $\left(m^{2}\right)$.

The diagnosis of $\mathrm{SH}$ was established when the thyroid stimulating hormone (TSH) levels were found on two separate occasions with an interval of 3 or 6 months to exceed the upper limit of the reference range $(4.0 \mathrm{mIU} / \mathrm{L})$, on the background of normal levels of free thyroxine (fT4) and free triiodothyronine (fT3). Serum thyroid hormone levels were determined by immunoassay method with SPL Granum kits (Ukraine). Ultrasound examination of the thyroid gland was performed according to the standard method on the LOGIQ 5 device.

The arterial blood pressure level (BP) was evaluated based on the average of three measurements at 2-minute intervals in sitting position. Glucose concentration determination was performed by glucose oxidase method on the Humolizer analyzer (made in Germany). Determination of the total cholesterol level (TC), triglycerides (TG) and high-density lipoprotein cholesterol (HDL-cholesterol) were performed in serum using the enzyme photocolorimetric method with sets produced by Human (Germany). The content of low density lipoprotein cholesterol (LDL-cholesterol) was calculated by the Friedewald W.T. formula with consideration of measurement in $\mathrm{mmol} / \mathrm{L}: L D L$-cholesterol $=T C-(H D L$-cholesterol + $+T G / 2.22)$.
Concentration of insulin in serum was measured by the method of enzyme immunoassay (ELISA) using diagnostic kits DRG Instrument Gmbh (Germany) on a semi-automatic enzyme immunoassay analyzer ImmunoChem-2100, High Technology, Inc. (USA).

To determine the insulin resistance (IR) index, HOMA-IR was used, which was calculated by the formula: [(glucose fasting) $\times$ (fasting insulin)] mmol/ ImL/22.5.

The level of glycated hemoglobin $\left(\mathrm{HbA}_{1 \mathrm{c}}\right)$ was determined by the immune enzyme method using "Hummer" kits (USA).

The condition of the vascular endothelium was studied by determining the level of VEGF-A in blood plasma by enzyme immunoassay (ELISA) using diagnostic kits from IBL International Gmbh (Germany) on a semi-automatic immunoassay microplate analyzer ImmunoChem-2100, High Technology, Inc. (USA).

The obtained results are presented as the average value of parameters $(\mathrm{M})$ and standard error $(\mathrm{m})$. Processing of statistical data was performed using the software package Statistics for Windows 8.0. The Student's criterion and Pearson's chi-squared test were used to evaluate the differences between groups in the distribution close to normal. A p-value $<0.05$ was considered statistically significant. To determine the effect of VEGF-A on various factors in observed patients, analysis of variance was used.

The study was performed in compliance with the basic provisions of the Helsinki Declaration of the World Medical Association on ethical principles of scientific and medical research involving human (1964-2000) and the order of the Ministry of Health of Ukraine No. 690 dated September 23, 2009. The study was approved by the Bioethics Commission at the Kharkiv National Medical University in accordance with the principles set forth in the Helsinki Declaration. The article is a fragment of the research work of the Department of Clinical Pharmacology and Internal Medicine of the Kharkiv National Medical University "Optimization of diagnosis and treatment of comorbid pathology (hypertension and type 2 diabetes mellitus) on the basis of evaluation of cardio-hemodynamic, metabolism and pharmacogenetic analysis" Registration No. 0118U000923.

\section{Results}

Selected patients regularly used standard antihypertensive therapy, which was the study inclusion criterion. Therefore, there were no significant dif- 
Table I. Selected characteristics of the study groups $(\mathrm{M} \pm \mathrm{m})$

\begin{tabular}{|l|c|c|c|c|}
\hline Parameter & $\begin{array}{c}\text { Control } \\
(\mathbf{n}=\mathbf{2 0})\end{array}$ & $\begin{array}{c}\text { Group 1 } \\
(\mathbf{n}=\mathbf{5 5})\end{array}$ & $\begin{array}{c}\text { Group 2 } \\
\text { (n=97) }\end{array}$ & $\begin{array}{c}\text { Group 3 } \\
\text { (n=59) }\end{array}$ \\
\hline SBP $[\mathrm{mm} \mathrm{Hg}]$ & $125.2 \pm 3.8$ & $139.4 \pm 6.6^{1}$ & $145.5 \pm 3.3^{1}$ & $150.6 \pm 5.8^{1}$ \\
\hline DBP $[\mathrm{mm} \mathrm{Hg}]$ & $78.2 \pm 7.1$ & $88.4 \pm 5.6$ & $94.3 \pm 4.2^{1}$ & $96.3 \pm 5.7^{1}$ \\
\hline BMI $\left[\mathrm{kg} / \mathrm{m}^{2}\right]$ & $22.12 \pm 2.51$ & $26.46 \pm 1.21^{1}$ & $29.52 \pm 1.03^{2}$ & $33.01 \pm 2.14^{1,2,3}$ \\
\hline TSH [mlU/L] & $2.1 \pm+0.53$ & $2.1 \pm 0.68$ & $2.48 \pm 0.79$ & $6.51 \pm 1.84^{1,2,3}$ \\
\hline TC [mmol/L] & $4.77 \pm 0.52$ & $5.29 \pm 0.81$ & $5.66 \pm 0.93$ & $5.93 \pm 0.96$ \\
\hline LDL-cholesterol $[\mathrm{mmol} / \mathrm{L}]$ & $2.6 \pm 0.33$ & $2.91 \pm 0.61$ & $3.06 \pm 0.11$ & $3.58 \pm 0.73$ \\
\hline HDL-cholesterol $[\mathrm{mmol} / \mathrm{L}]$ & $1.49 \pm 0.30$ & $1.26 \pm 0.06$ & $1.19 \pm 0.12$ & $1.15 \pm 0.08$ \\
\hline TG $[\mathrm{mmol} / \mathrm{L}]$ & $1.00 \pm 0.30$ & $1.63 \pm 0.12^{1}$ & $1.78 \pm 0.21^{1}$ & $2.34 \pm 0.23^{1,2,3}$ \\
\hline Blood fasting glucose $[\mathrm{mmol} / \mathrm{L}]$ & $4.63 \pm 0.52$ & $5.36 \pm 0.17$ & $8.02 \pm 0.62^{1,2}$ & $7.47 \pm 0.81^{1,2}$ \\
\hline Insulin fasting $[\mu / \mathrm{lU} / \mathrm{mL}]$ & $9.8 \pm 1.16$ & $17.46 \pm 2.07^{1}$ & $22.34 \pm 3.44^{1}$ & $20.06 \pm 3.21^{1}$ \\
\hline HbA ${ }_{1 \mathrm{c}}(\%)$ & $4.62+1.08$ & $5.81 \pm 0.38$ & $7.16+1.08^{1}$ & $7.27 \pm 1.87^{1}$ \\
\hline HOMA-IR & $2.23 \pm 0.36$ & $4.07 \pm 0.59^{1}$ & $8.17 \pm 1.37^{1,2}$ & $6.34 \pm 1.53^{1,2}$ \\
\hline VEGF-A [pg/mL] & $127.50 \pm 21.88$ & $413.15 \pm 29.05^{1,3}$ & $323.94 \pm 22.17^{1}$ & $398.06 \pm 26.82^{1,3}$ \\
\hline
\end{tabular}

TC — total cholesterol; LDL-cholesterol — low-density lipoprotein cholesterol; HDL-cholesterol — high-density lipoprotein cholesterol; TG — triglycerides; SBP — systolic blood pressure; DBP — diastolic blood pressure; $\mathrm{BMI}$ - body mass index; TSH — thyroid stimulating hormone; $\mathrm{HbA}_{1 \mathrm{c}}$ - glycated hemoglobin, HOMA-IR — insulin resistance (IR) index; VEGF-A — vascular endothelial growth factor $\mathrm{A}$; $p<0.05$ vs. the control group; ${ }^{2} p<0.05$ vs. the Group $1 ;{ }^{3} p<0.05$ vs. the Group 2

ferences between the groups in the mean values of both systolic blood pressure (SBP) and diastolic blood pressure (DBP), despite different comorbidities (Tab. I).

Patients in all studied groups had hypercholesterolemia. The presence of comorbid pathology in the form of a combined course of hypertension and T2DM in patients of the Group 2 was accompanied by a more pronounced dyslipidemia than in patients with isolated HT (Group 1). The attachment of SH to HT and T2DM was accompanied by the emergence of a tendency for the growth of all investigative indexes of lipid metabolism (see Tab. I).

Analysis of carbohydrate metabolism parameters showed the sings of IR in all studied patients groups. In our study, despite the existence of significant differences between the study subjects and the control group, the plasma insulin levels remained within the reference values [Groups 1, 2, 3, respectively: $17.46 \pm$ $\pm 2.07 \mu \mathrm{M} / \mathrm{mL}, 22.34 \pm 3.44 \mu \mathrm{M} / \mathrm{mL} ; 20.06 \pm$ $\pm 3.21 \mu \mathrm{M} / \mathrm{mL}$; control group $-9.8 \pm 1.16 \mu \mathrm{M} /$ $/ \mathrm{mL}(\mathrm{p}<0.05)]$.

The analysis of VEGF-A in patients with isolated hypertension showed a significantly higher levels of this parameter than in the control group [ $413.15 \pm$ $\pm 29.05 \mathrm{pg} / \mathrm{mL}$ and $127.50 \pm 21.88 \mathrm{pg} / \mathrm{mL}$, respectively $(\mathrm{p}<0.05)$ ]. Patients with combined course of hypertension and T2DM had significantly lower VEGF-A levels compared to patients with isolated HT [323.94 $\pm 22.17 \mathrm{pg} / \mathrm{mL}$ and $413.15 \pm 29.05$ $\mathrm{pg} / \mathrm{mL}$, respectively $(\mathrm{p}<0.05)]$, but significantly higher than in the control group $(\mathrm{p}<0.05)$. In patients with combined course of HT, T2DM and $\mathrm{SH}$, the level of VEGF-A $(398.06 \pm 36.82 \mathrm{pg} / \mathrm{mL})$ was significantly higher than in controls ( $\mathrm{p}<0.05)$, not significantly lower than in Group 1 patients $(p>0.05)$ and significantly higher than in Group 2 patients $(\mathrm{p}<0.05)$. The results of analysis of variance showed a significant influence of VEGF-A on insulin $(\mathrm{p}<0.001)$ and HOMA-IR index $(\mathrm{p}=0.036)$ in patients with HT, T2DM and $\mathrm{SH}$, whereas in other investigated groups no significant effect of VEGF-A on the studied parameters was detected. Taking into account the aggravation of most of the typical SH disturbances with the increase in TSH, its range of $4.0-10.0 \mathrm{mU} / \mathrm{L}$ is large enough and may contain levels of great importance for specific categories of patients. Based on this assumption, all patients of Group 3 were divided into 3 subgroups in order to clarify the influence of TSH levels on the levels of VEGF-A. Group 3a $(\mathrm{n}=26)-\mathrm{TSH}$ levels 4.0-6.0 mIU/L; group $3 \mathrm{~b}(\mathrm{n}=20)-\mathrm{TSH}$ levels 6.1-8.0 mIU/L; and group $3 \mathrm{c}(\mathrm{n}=13)-\mathrm{TSH}$ levels $8.1-10 \mathrm{mIU} / \mathrm{L}$. Despite the fact that such distribution of patients is clinically inexpedient, VEGF-A levels differed (Fig. 1).

Plasma levels of VEGF-A were the lowest in $3 \mathrm{a}$ subgroup $(375.91 \pm 19.81 \mathrm{pg} / \mathrm{mL})$, significantly different from $3 b$ and $3 c$ subgroups $(\mathrm{p}<0.05)$, for which practically no differences were found $(3 \mathrm{~b}-416.31 \pm 17.64 \mathrm{pg} / \mathrm{mL}, 3 \mathrm{c}-414.68 \pm 19.24$ $\mathrm{pg} / \mathrm{mL}$, respectively, $\mathrm{p}>0.05$.) These data coincide with the opinion of a number of authors who consider the levels of TSH of 6-7 mIU/L as the thresh- 


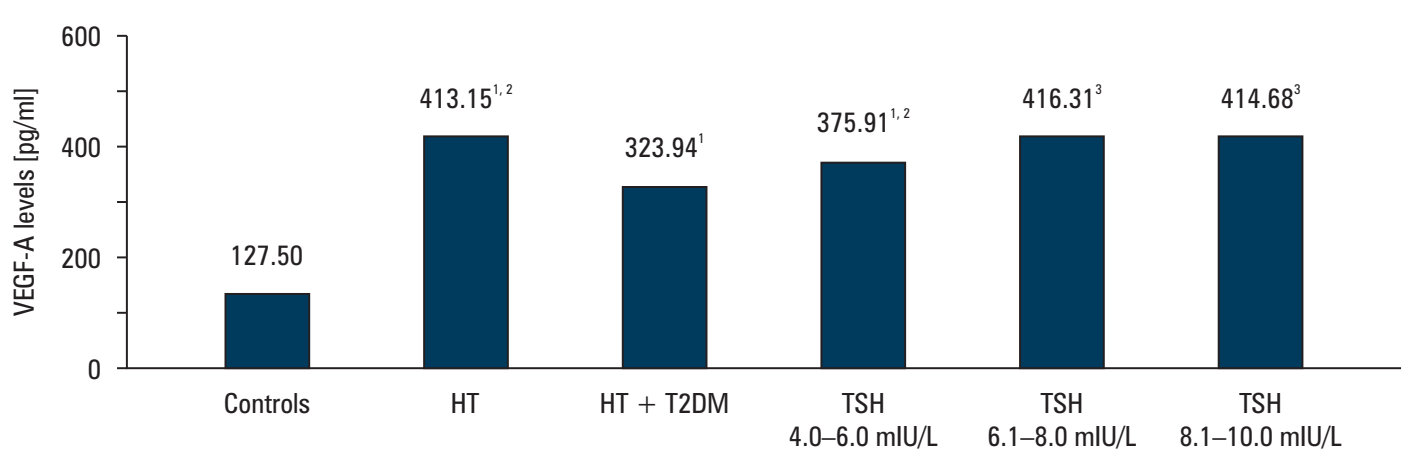

Figure 1. Vascular endothelial growth factor A (VEGF-A) levels depending on thyroid-stimulating hormone (TSH) levels ('p $<0.05 \mathrm{vs.} \mathrm{controls;}$ ${ }^{2} \mathrm{p}<0.05$ vs. HT with T2DM group; ${ }^{3} \mathrm{p}<0.05$ vs. TSH 4.0-6.0 mlU/L subgroup); HT — hypertension; T2DM — type 2 diabetes mellitus

old from the point of view of cardiovascular risk [10]. We analyzed the levels of VEGF-A in patients of Group 3, taking into account the levels of TTH up to $7.0 \mathrm{mIU} / \mathrm{L}$ and TSH levels between 7.1 and $10.0 \mathrm{mIU} / \mathrm{L}$. The following results were obtained: in patients with a slight TSH levels' increase (up to 7.0 $\mathrm{mIU} / \mathrm{L}$, mean value: $5.64 \pm 1.07 \mathrm{mIU} / \mathrm{L}$ ), VEGF-A levels were $382.33 \pm 16.71 \mathrm{pg} / \mathrm{mL}$, which was lower than those with TSH levels above $7.1 \mathrm{mIU} / \mathrm{L}$ (mean value: $8.87 \pm 1.11 \mathrm{mIU} / \mathrm{L})-423.49 \pm 21.11 \mathrm{pg} / \mathrm{mL}$ $(\mathrm{p}<0.05$, respectively).

\section{Discussion}

Lipid metabolism changes in patients of different groups in the present study coincide with the results of the HUNT study, which demonstrated a direct relationship between the level of TSH and blood lipids levels, which was manifested even within the normal values of TSH: the higher the content of $\mathrm{TSH}$, the higher level of cholesterol [11]. The results of this research confirm the existing data on the presence of atherogenic dyslipidemia on the background of incomplete thyroid metabolism compensation as a risk factor for the progression of atherosclerosis and, accordingly, the risk of its complications development, as demonstrated also in a number of major studies [12]. The feasibility of L-thyroxine therapy in patients with $\mathrm{SH}$ is still the subject of scientific and practical discussions, because there are a number of studies that did not confirm any influence of thyroid subclinical hypo function on lipid metabolism [12, 13]. However, it is indisputable the fact that for the treatment of dyslipidemia in hypothyroidism the use of the low-cholesterol diet and hypolipidemic agents may be insufficient.
The presence of IR in the T2DM is not in doubt; in the case of $\mathrm{SH}$ is still controversial, but for the combination of T2DM and $\mathrm{SH}$ there is virtually no data. Noteworthy is the fact that in studies in which IR in SH was not detected, the authors found hyperinsulinemia as the first sign of glucose metabolism impairment. The presence of a significantly higher HOMA-IR in patients of Group 2 compared with Group 1 (patients with isolated hypertension) is expected and does not require explanation. Reducing this index when HT and T2DM combined with $\mathrm{SH}$ in Group 3 patients requires a deeper study of this issue. Perhaps this is due to the fact, that thyroid hormones are not only antagonists of insulin and exhibit counter-insular action, but according to their influence on peripheral tissues, they are also synergists of insulin and contribute to the transportation and utilization of glucose.

In recent years, it has been established that an increase in serum VEGF-A levels is a risk factor for the development of cardiovascular pathology and its complications. Today, VEGF-A and its physiological activity are of great interest and create many contradictions. Its significant increase in the group of patients with isolated hypertension compared with controls in our study coincides with the available literature showing the important role of VEGF-A in the cardiovascular diseases, in particular in hypertension [2].

Vascular endothelial growth factor is an important bioactive substance that is involved in the development of vascular complications in diabetes mellitus. However, currently available data on VEGF-A levels in diabetes mellitus and its complications are quite controversial. In the literature, there are studies that describe both the increase and the decrease in VEGFA levels in this pathology. VEGF-A has been success- 
fully used to treat ischemia with diabetic limb lesions. On the other hand, VEGF-A inhibition was used in diabetic retinopathy [4]. Lower values of VEGF-A in a combination of hypertension with T2DM versus isolated $\mathrm{AH}$ may be explained by the fact that in the present study, all patients with T2DM at the time of inclusion received Metformin. At present, there are numerous data, including those obtained in randomized trials, concerning the beneficial effects of Metformin on the function of endothelium [14]. Thus, Wu $S$ et al. (2014) demonstrated that the use of Metformin over a period of 12 months resulted in a significant improvement in endothelium function [15]. The decrease in the degree of ED partially explains a decrease in the morbidity and complications of the CV system in patients with T2DM [16].

It is known that the thyroid system actively interacts with different neurohumoral links involved in the regulation of the CV system [11 12]. Data on the relation between $\mathrm{SH}$ and ED currently remain controversial. The decrease in endotheliumdependent vasodilatation (EDVD) in patients with hypothyroidism is supposed to be a demonstration of the triiodothyronine deficiency. There is also evidence of vascular endothelial damage under the influence of immune complexes on the background of chronic AIT, which can exacerbate the manifestations of ED.

There is evidence of a connection of high level of TSH with increased levels of total cholesterol, LDL-cholesterol and presence of ED [3].

The study of VEGF-A levels at varying degrees of TSH increase confirms the hypothesis of increased ED in hypothyroidism already at the subclinical level, despite the presence of factors contributing to its improvement (in the present study, the use of Metformin). Depression of ED occurs even with insignificant increase in TSH: VEGF-A level in subgroup with HT, T2DM and SH with TSH levels 4.0-6.0 mIU/L was higher than in patients with a combined course of hypertension and diabetes mellitus, but with normal thyroid function $(375.91 \pm 19.81 \mathrm{pg} / \mathrm{mL}$ and $323.94 \pm 22.17 \mathrm{pg} / \mathrm{mL}$, respectively, $\mathrm{p}<0.05)$.

\section{Conclusions}

1. Among the studied hypertensive patients with different concomitant diseases, ED was most pronounced in patients with a combined course of hypertension, T2DM and $\mathrm{SH}$.

2. The simultaneous course of HT and T2DM was accompanied by the presence of $\mathrm{ED}$, which was manifested by elevated levels of VEGF-A compared with the control group, but to a much lesser extent than with isolated HT, which could be explained by additional endothelial-protective effects of metformin.

3. Thyroid dysfunction, accompanied by an insignificant increase in TTH, leads to a much more significant $\mathrm{ED}$, than with comorbid states with normal thyroid function, which manifested in a significant increase in VEGF-A.

\section{References}

1. Kuryata OV, Grechanyk MM. [Functional condition of vascular endothelium in patients with coronary heart disease in combination with non-alcoholic fatty liver disease, depending on weight and influence of statin therapy]. Zaporozhye Med J. 2015(1), doi: $10.14739 / 2310-1210.2015 .1 .38626$.

2. Makurina GI. [Study of the vascular endothelium mechanisms activation in patients with psoriasis and arterial hypertension]. Zaporozhye Med J. 2016(94): 19-24, doi: 10.14739/23101210.2016.1.64070.

3. Smirnova E.N., Shulkina S.G., Schekotov V.V., Antipova A.A. [Vascular endothelial growth factor as a marker of endothelial dysfunction and early kidney damage in patients with metabolic syndrome]. Modern problems of science and education. Sep 2015. https:// www.science-education.ru/ru/article/view?id=21800 (2018 Nov 16).

4. Vural P, Kabaca G, Firat RD, et al. Administration of Selenium Decreases Lipid Peroxidation and Increases Vascular Endothelial Growth Factor in Streptozotocin Induced Diabetes Mellitus. Cell J. 2017; 19(3): 452-460, doi: 10.22074/cellj.2017.416, indexed in Pubmed: 28836407.

5. Mancia G, Fagard R, Narkiewicz K, et al. Task Force Members. 2013 ESH/ESC Guidelines for the management of arterial hypertension: the Task Force for the management of arterial hypertension of the European Society of Hypertension (ESH) and of the European Society of Cardiology (ESC). J Hypertens. 2013; 31(7): 1281-1357, doi: 10.1097/01.hjh.0000431740.32696.cc, indexed in Pubmed: 23817082.

6. Ministry of the Health of Ukraine. Order of the Ministry of Health of Ukraine dated 22 May.2009 No 356 "On approval of medical aid protocols for patients with endocrine diseases". 2009, May. http://www. moz.gov.ua/ua/portal/dn_20090805_574.html (2009, May 22).

7. Ministry of the Health of Ukraine. Order of the Ministry of Health of Ukraine dated 21. Dec. 2012 No 1118 "On Approval and Implementation of Medical-Technological Documents for the Standardization of Medical Aid in Type 2 Diabetes". 2012, Dec . https://medprosvita.com.ua/nakaz-moz-ukrayini-vid-21-122012-n-1118-pro-zatver/ (2012, Dec. 21).

8. Inzucchi SE, Bergenstal RM, Buse JB, et al. Management of hyperglycemia in type 2 diabetes, 2015: a patient-centered approach: update to a position statement of the American Diabetes Association and the European Association for the Study of Diabetes. Diabetes Care. 2015; 38(1): 140-149, doi: 10.2337/dc14-2441, indexed in Pubmed: 25538310.

9. Pearce SHS, Brabant G, Duntas LH, et al. 2013 ETA Guideline: Management of Subclinical Hypothyroidism. Eur Thyroid J. 2013; 2(4): 215-228, doi: 10.1159/000356507, indexed in Pubmed: 24783053.

10. McQuade C, Skugor M, Brennan DM, et al. Hypothyroidism and moderate subclinical hypothyroidism are associated with increased all-cause mortality independent of coronary heart disease risk factors: a PreCIS database study. Thyroid. 2011; 21(8): 837-843, doi: 10.1089/thy.2010.0298, indexed in Pubmed: 21745107.

11. Asvold BO, Vatten LJ, Nilsen TIL, et al. The association between $\mathrm{TSH}$ within the reference range and serum lipid concentrations in 
a population-based study. The HUNT Study. Eur J Endocrinol. 2007; 156(2): 181-186, doi: 10.1530/eje.1.02333, indexed in Pubmed: 17287407.

12. Blankova ZN, Ageev FT, Seredenina EM et al [Hypothyroidism and cardio-vascular diseases]. Russian Med J. 2014(13): 980. https://www.rmj.ru/articles/endokrinologiya/gipotireoz-iserdechno-sosudistye-zabolevaniya/\#ixzz5X3TYvMkE (2018 Nov 16).

13. Budnevskiy AV, Kravchenko AY, Feskova AA et al. [Dyslipidemia in subclinical hypofunction of the thyroid gland and the effectiveness of its correction by L-thyroxin replacement therapy]. Young Scientist 2014;17(76):138-142. https://moluch.ru/archive/76/12981/ (2018 Nov 16).
14. Hamidi Shishavan M, Henning RH, van Buiten A, et al. Metformin Improves Endothelial Function and Reduces Blood Pressure in Diabetic Spontaneously Hypertensive Rats Independent from Glycemia Control: Comparison to Vildagliptin. Sci Rep. 2017; 7(1): 10975, doi: 10.1038/s41598-017-11430-7, indexed in Pubmed: 28887562

15. Wu S, Li X, Zhang H. Effects of metformin on endothelial function in type 2 diabetes. Exp Ther Med. 2014; 7(5): 1349-1353, doi: 10.3892/etm.2014.1582, indexed in Pubmed: 24940437.

16. de Jager J, Kooy A, Schalkwijk C, et al. Long-term effects of metformin on endothelial function in type 2 diabetes: a randomized controlled trial. J Intern Med. 2014; 275(1): 59-70, doi: 10.1111/ joim.12128, indexed in Pubmed: 23981104. 